\title{
Interaction of two rivulets on the bottom side of an inclined plate
}

\author{
Ekaterina Slesareva $^{1 \mathrm{a}}$, Ruslan Dekhtyar ${ }^{1}$, and Valeriy Ovchinnikov ${ }^{1}$ \\ ${ }^{1}$ SB RAS, Kutateladze Institute of Thermophysics, 630090 Novosibirsk, Russia
}

\begin{abstract}
The flow of rivulets and droplets over the bottom side of inclined hydrophobic surface was studied in this work. Interacting of two nearby draining rivulets is investigated. Distilled water was used as the working liquid. The experiments were carried out on the bottom side of a smooth plate with the width of $440 \mathrm{~mm}$ and length of $1400 \mathrm{~mm}$. The angle of plate surface deviation from the vertical was $14^{\circ}$. The switching centre consisted of two nozzles with diameter of $0.8 \mathrm{~mm}$. Tubes placed perpendicularly plate surfaces on distance of $10 \mathrm{~mm}$ from each other. The experiments were carried out at the flow rates from 0.1 to $1.0 \mathrm{ml} / \mathrm{s}$, and flow rate supported constant. The flow patterns were recorded video with the speed of $1200 \mathrm{fps}$. It was shown at a constant liquid flow rate at the nozzle exit the direction of and shape of the rivulet depend on maldistribution of the liquid flow rate along the rivulet. It is shown, that the regime of flow rivulet can be changed by interacting with another rivulet. Change regime of flow of rivulet occurs according to the laws defining character of a current of a liquid in rivulet.
\end{abstract}

\section{Introduction}

Use a film of liquid in heat exchangers (condensers, absorbers, distillation columns, etc.), does of great importance study of such flow. Experimental and theoretical researches have shown, that the structure of a film flow strongly influences on local and average characteristics heat-and-mass transfer. One the forms of streaming down the liquid on an inclined surface are rivulet. At small flow rates of a liquid streamlet disintegration on drops is observed. On rivulet motion loom large a wetting angle and its hysteresis [1], that leads to that rivulet moves in the unpredictable way in the form of a snake (meandering) owing to what it is impossible define univocal characteristics of rivulet path[2]. In the literature there is a considerable quantity of experimental data for a flow rivulet and a drop [2 - 5]. However major portion they are obtainment for the upper side of a plate or for vertical surfaces. For flow of liquid on the bottom side of an inclined plate the quantity of data is restricted. The purpose of the present work is the experimental research transient regime for flow of a rivulet and a drop on the bottom side of an inclined hydrophobic surface.

\section{A measurement procedure}

\section{a Corresponding author: styuardessa@yandex.ru}


Experiments were spent on a smooth plate from polyethylene 1 in length of $1400 \mathrm{~mm}$ and width $300 \mathrm{~mm}$. The slope of a surface of a plate made concerning a vertical $\theta=14^{\circ}$. Marriott's vessel 2 supported a constant outlet pressure of the switching centre. The flow rate was controlled by means of the valve 3 . The switching centre consisted of two polyethylene submitting tubes (nozzle) with a diameter of $0.8 \mathrm{~mm}$. Tubes placed perpendicularly plate surfaces on distance of $10 \mathrm{~mm}$ from each other on the plate centre. The positive allowance between a surface of a plate and a shearing of submitting tubes did not exceed $0.5 \mathrm{~mm}$. The liquid flow rate was measured by volume method (before and after experiment by a video camera 5 process of filling gage tank 6 carry out), accuracy of measurement of the flow rate made $0.002 \mathrm{ml} / \mathrm{s}$. The weight of drops on a surface was defined by a weight method to within $0.5 \mathrm{mg}$. Flow pattern on the bottom side a plate by a high-speed digital video cameras 7 video filming was carried out for different sections by height. Video filming was carried out from speed up to $1200 \mathrm{fps}$. Reference point for coordinate $Y$ along a plate was on the bottom edge of a plate.

Running off of the rivulet on the bottom party of a plate by gravity, and also interaction was investigated by two rows of the flowing-down rivulet. Distilled water was used as the working liquid. The liquid flow rate changed from 0.01 to $1.0 \mathrm{ml} / \mathrm{s}$ and was supported to constants. Constancy of flow rate was controlled before and after carrying out experiment. At processing of frames the velocity and accelerations of the separate structures which are visually on rivulet were measured.

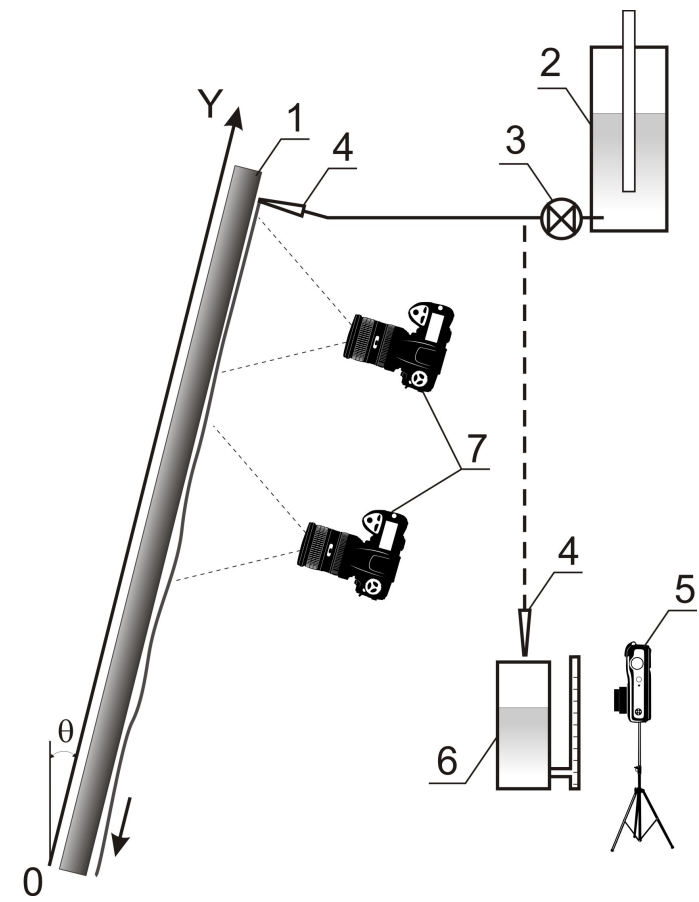

Figure 1. Scheme of experimental facility. 1 - a plate from polyethylene, 2 - Marriott's vessel, 3 - the valve, 4 nozzle, 5 - a digital video camera, 6 - a gage tank, 7 - a high-speed digital video camera

\section{Discussion of results}

The flow of rivulets and droplets over the bottom side of inclined hydrophobic surface was studied. It was shown for the droplet and rivulet-droplet flows: at a constant liquid flow rate at the nozzle exit the direction of and shape of the rivulet depend on maldistribution of the liquid flow rate along the rivulet.

In-process [6] it is shown, that in a regime non-stationary meandering in various cross-sections on length rivulet originate «varicose» the perturbations connected with change of the flow rate. As a result of development of "varicose" disturbance are formed one or more points of bifurcation with 
formation of the accruing finger-shaped structures that leads to change of the direction of a rivulet flow in bifurcation points.

For a regime non-stationary meandering prevention experiments with interacting non-stationary meandering rivulet and rivulet-droplet has been in special way organised have been carry out. For a regime non-stationary meandering prevention experiments with interacting non-stationary meandering rivulet and rivulet-droplet has been in specially organised have been carry out. For example, on fig. 2 and fig. 3 it is shown as there is an interacting of two rivulets to various flows. The video filming was take for two sections along the length of a plate from an location of feeding tube (the first section $1.32 \div 1.20$, second $1.03 \div 0.91 \mathrm{~m}$ ). Frequency of droplet detachment from left rivulet an order of $2.5 \mathrm{~Hz}$. In a current $6 \div 7$ seconds after supply of a liquid on nozzle are formed meandering nonsteady rivulet. On fig. 2 it is visible, that as a result of interacting of drops a low flow rating rivulet with meandering non-steady rivulet in five seconds after the interaction of two rivulets one is formed rivulet with low-level meandering.
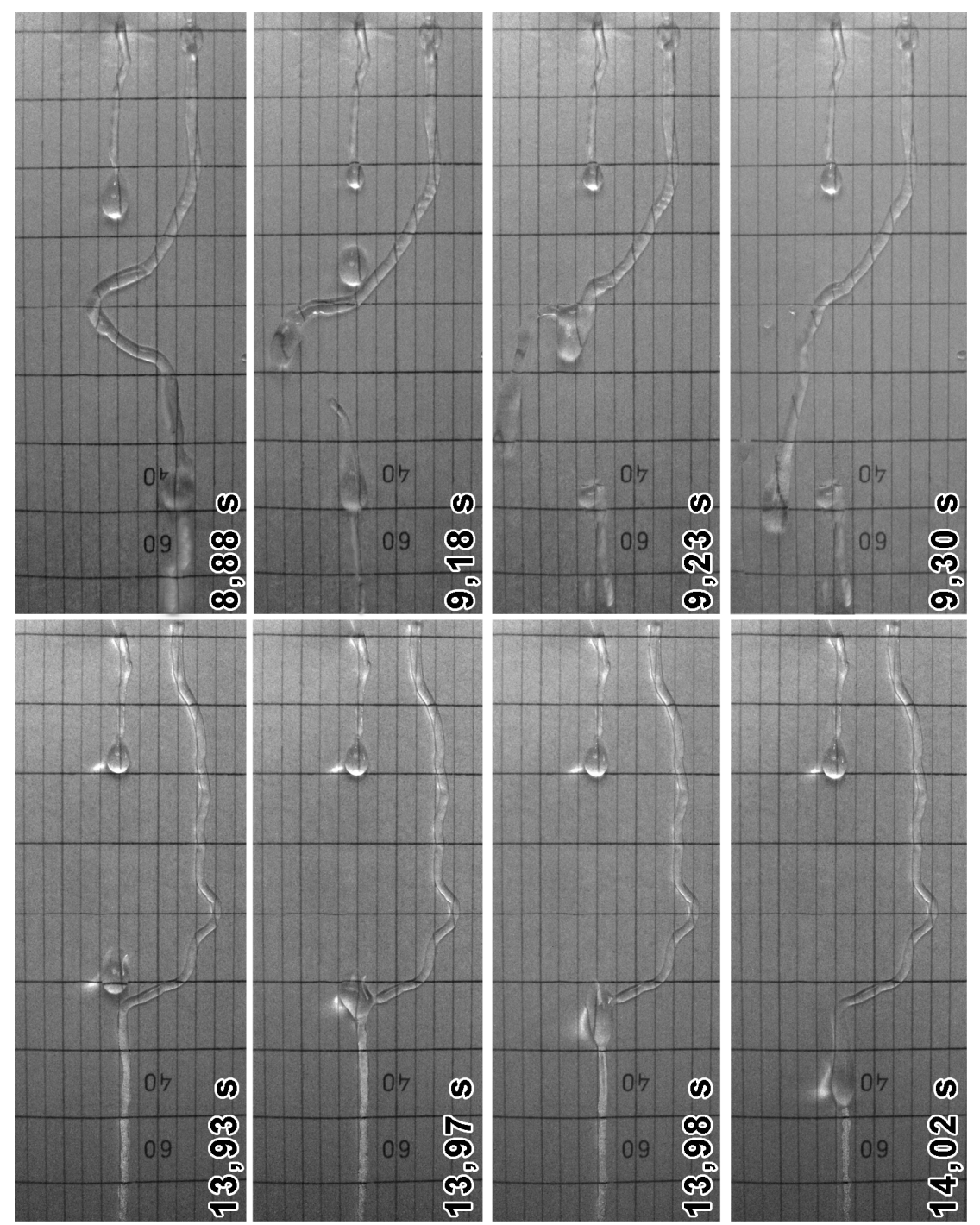

Figure 2. Frames of a high-speed video process of interacting of two rivulets, the flow rate $q_{1}=0.530 \mathrm{ml} / \mathrm{s}$, $q_{2}=0.053 \mathrm{ml} / \mathrm{s}$. On frames show the time from the moment of supply of a liquid on nozzle. 
On fig. 3 changing on rivulet $\left(q_{1}=0.530 \mathrm{ml} / \mathrm{s}\right)$ location of the bottom border a "drop" formed on falling edge a low flow rating rivulet $\left(q_{2}=0.053 \mathrm{ml} / \mathrm{s}\right)$ is shown. It is visible, that before contact with the core rivulet the drop slowly slips on an emulsion carrier. After merge velocity of a drop rapidly increases. However in process of "drop" moving on rivulet of sliding acceleration "varicose" perturbations decreases from $4 \mathrm{~m} / \mathrm{s}^{2}$ in a point of the joint to $0.5 \mathrm{~m} / \mathrm{s}^{2}$ in the bottom part of a plate. Drops have a influence on effect of stabilizing for meandering rivulet not only below a merge point, but also above.

That is the disturbances occurrence on rivulet, have an influence on both downwards and upstream streams. Thus, the accelerated motion of "drop" have a influence on effect of stabilizing for meandering rivulet. Such example shows, that understanding the laws defining character of a current of a liquid in rivulet, helps to control of flow regime.

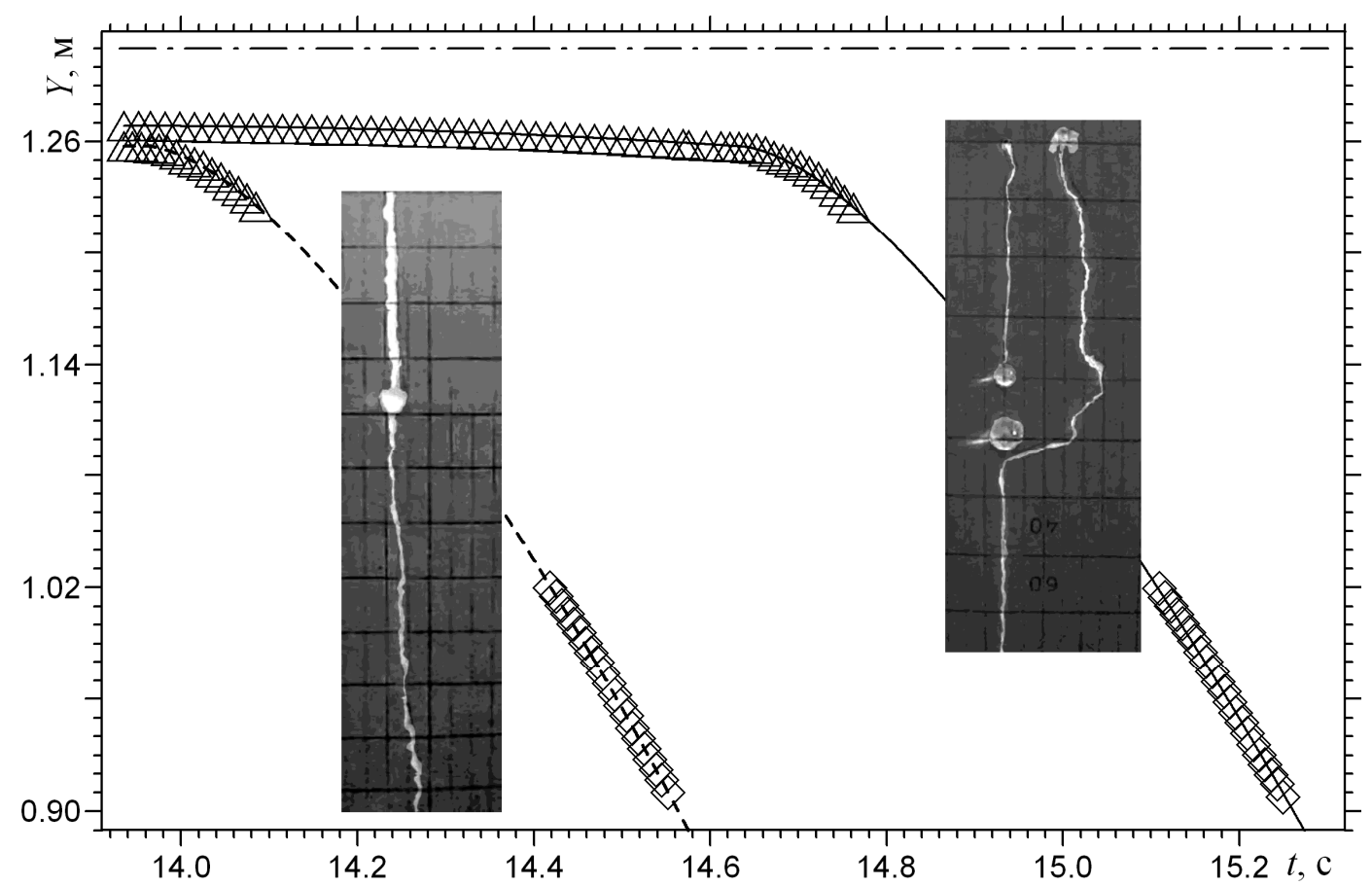

Figure 3. Changing on rivulet $\left(q_{1}=0.530 \mathrm{ml} / \mathrm{s}\right)$ location of the bottom border a "drop" formed on falling edge a low flow rating rivulet $\left(q_{2}=0.053 \mathrm{ml} / \mathrm{s}\right)$. The first section $1,32 \div 1,20 \mathrm{~m}$, second $1,03 \div 0,91 \mathrm{~m}$. Dash-dot line $1,31 \mathrm{~m}$ - a location of nozzle.

It is shown, that the regime of flow rivulet can be changed by interacting with another rivulet. Change regime of flow of rivulet occurs according to the laws defining character of a current of a liquid in rivulet.

Acknowledgements. This work was done under a grant from the Russian Science Foundation N 14-19-00352.

\section{References}

1. G.D. Towell,L.B. Rothfeld, Int. J. Heat Mass Trans., 12(5), 972, (1966)

2. T. Nakagawa, J.C. Scott, J. Fluid Mech., 149, 89, (1984)

3. V.E. Nakoryakov, S.Y. Misyura, Chem. Engin. Scien., 104, 1, (2013)

4. V.E. Nakoryakov, S.Y. Misyura, S.L. Elistratov, J. Engin. Therm., 22(1), 1, (2013)

5. S.Ya. Misyura, Int. J. Heat Mass Trans., 71, 197, (2014)

6. V.E. Nakoryakov, V.M. Ovchinnikov, R.A. Dekhtyar, Modern Scien., 12(1), 90, (2013) 